\title{
əVerification of Heat Stress Thresholds for a Health-Based Heat-Wave Definition $\mathscr{a}$
}

\author{
Claudia Di NAPOLI \\ Department of Geography and Environmental Science, University of Reading, Reading, United Kingdom \\ FLORIAN PAPPENBERGER \\ Forecast Department, European Centre for Medium-Range Weather Forecasts, Reading, United Kingdom \\ HANNAH L. ClOKE \\ Department of Geography and Environmental Science, and Department of Meteorology, University of Reading, \\ Reading, United Kingdom, and Department of Earth Sciences, Uppsala University, and Centre of Natural \\ Hazards and Disaster Science, Uppsala, Sweden
}

(Manuscript received 18 September 2018, in final form 26 February 2019)

\begin{abstract}
Heat waves represent a threat to human health and excess mortality is one of the associated negative effects. A health-based definition for heat waves is therefore relevant, especially for early warning purposes, and it is here investigated via the universal thermal climate index (UTCI). The UTCI is a bioclimate index elaborated via an advanced model of human thermoregulation that estimates the thermal stress induced by air temperature, wind speed, moisture, and radiation on the human physiology. Using France as a test bed, the UTCI was computed from meteorological reanalysis data to assess the thermal stress conditions associated with heat-attributable excess mortality in five cities. UTCI values at different climatological percentiles were defined and evaluated in their ability to identify periods of excess mortality (PEMs) over 24 years. Using verification metrics such as the probability of detection (POD), the false alarm ratio (FAR), and the frequency bias (FB), daily minimum and maximum heat stress levels equal to or above corresponding UTCI 95th percentiles $\left(15^{\circ} \pm 2^{\circ} \mathrm{C}\right.$ and $34.5^{\circ} \pm 1.5^{\circ} \mathrm{C}$, respectively) for 3 consecutive days are demonstrated to correlate to PEMs with the highest sensitivity and specificity $(0.69 \leq \mathrm{POD} \leq 1,0.19 \leq \mathrm{FAR} \leq 0.46,1 \leq \mathrm{FB} \leq 1.48)$ than minimum, maximum, and mean heat stress level singularly and other bioclimatological percentiles. This finding confirms the detrimental effect of prolonged, unusually high heat stress at day- and nighttime and suggests the UTCI 95th percentile as a health-meaningful threshold for a potential heat-health watch warning system.
\end{abstract}

\section{Introduction}

The summer of 2003 represented a turning point in the study of heat waves and their impacts on human health. The deaths of more than 70000 people, caused by sustained, excess heat that dominated Europe in that period,

๑ Denotes content that is immediately available upon publication as open access.

Supplemental information related to this paper is available at the Journals Online website: https://doi.org/10.1175/JAMC-D-180246.s1.

Corresponding author: Claudia Di Napoli,c.dinapoli@reading.ac.uk urged most affected countries to implement heat-health action plans for the first time (Robine et al. 2008). Since 2003, warning systems based on meteorological forecasts have been put in place by governments across the continent to anticipate heat waves and reduce related excess mortality through the timely notification of prevention measures. Prevention measures are addressed both to the general population and to vulnerable groups, such as the elderly, who are particularly at risk of heat-related mortality, and to first responders, that is, national health services, as heat-wave events are associated with increases

This article is licensed under a Creative Commons Attribution 4.0 license (http://creativecommons.org/ licenses/by/4.0/)

DOI: 10.1175/JAMC-D-18-0246.1 
in emergency hospital admissions and ambulance callouts (Kovats and Ebi 2006). Warning systems for health hazards in heat-wave conditions, known as heat-health watch warning systems (HHWWSs), use a variety of different indicators to identify and inform of a potentially hazardous heat-wave event (Lowe et al. 2011). The indicator mostly used in Europe is the 2-m air temperature. Parameters combining 2-m air temperature with relative air humidity, such as the apparent temperature or the heat index, are also adopted. The relationship between these indicators and mortality is well documented in literature (e.g., D'Ippoliti et al. 2010; Gasparrini et al. 2015).

Environmental conditions that are potentially detrimental to human health occur both indoors and outdoors (McGregor et al. 2015). In indoor settings, such as houses and offices, these are mainly represented by temperature, humidity, and thermal radiation. In nonsheltered, outdoor environments, other meteorological factors, such as wind and direct radiation, have to be considered. For instance, high temperatures and moisture levels combined with absence of ventilation and direct sunlight generate a heat load, called heat stress, that can undermine the human body's ability to maintain its core temperature within the range of optimal physiological performance (McGregor and Vanos 2018). As heat stress increases, the human thermoregulatory mechanism becomes compromised, the body produces or absorbs more heat than it dissipates, and the core internal temperature starts to rise causing discomfort, health disorders, and ultimately death. Indices that assess heat stress from the energythermal exchange between multiple environmental factors and the human body have been proposed (Havenith and Fiala 2016). One of these indices is the universal thermal climate index (UTCI).

Developed in 2009 by a multidisciplinary working group of leading experts in thermal physiology, occupational medicine, meteorology, and mathematical modeling, the UTCI is a bioclimate index that describes the heat stress to which the human body is exposed by considering the combined contribution of metabolic heat, meteorological parameters, and clothing requirements (Jendritzky et al. 2012). It is based on the UTCI-Fiala energy balance model, which simulates the physiological response of an individual to an outdoor environment via a multinode thermoregulation model coupled with a temperature-adaptive clothing insulation model (Fiala et al. 2012; Havenith et al. 2012). Valid in all climates and seasons, as well as on spatial and temporal scales from the micro- to the macroscale, the UTCI has been extensively used to characterize heat stress conditions and investigate related effects on human health across a variety of locations in Europe (Błażejczyk et al. 2010b; Nemeth 2011; Nastos and Matzarakis 2012; Błażejczyk and Błażejczyk 2014; Bleta et al. 2014; Matzarakis et al. 2014; Urban and Kyselý 2014; Burkart et al. 2016; Mạkosza and Nidzgorska-Lencewicz 2017; Kolendowicz et al. 2018; Di Napoli et al. 2018). Following these results, the potential of the UTCI has started to be explored also in an operational context with in the implementation of forecasting and warning systems. UTCI-based forecast tools for outdoor thermal comfort have been developed and made publicly available in the Netherlands (Heusinkveld et al. 2017). The predictive skill of UTCI forecasts has also been tested and proved successful in detecting hazardous heat stress levels up to 10 days in advance (Pappenberger et al. 2015). As interest and research efforts increase in the topic, the necessity arises to test the capability of UTCI as an impact-based indicator for heat-wave health hazards in a prospective HHWWS.

Current HHWWSs provide an ideal platform to identify and define heat stress conditions that might adversely affect human health. They are "action trigger" based, that is, a heat-health warning is issued when a selected indicator is forecast to likely exceed a given threshold in the near future. The threshold has significance for health effects and is usually defined from historical heat-health relationships (Koppe et al. 2004; McGregor et al. 2015). One of the most documented HHWWS is the system currently operative in France (Pascal et al. 2006; Pascal et al. 2013; Antics et al. 2013). Developed soon after the 2003 European heat wave, the French HHWWS is based on an air temperature-dependent indicator and activates national public health interventions when the indicator exceeds a value that a retrospective analysis of mortality and meteorological data has demonstrated to be associated with heat-attributable increase of deaths. The system has been tested in different cities. For each city threshold values have been chosen so they are able to anticipate days when mortality is above the historical level observed for the period (Pascal et al. 2013). Days identified via epidemiological studies with heat-attributable excess mortality can be used to characterize heat stress thresholds hazardous to health.

Following this rationale, the present paper aims 1) to investigate the UTCI as a heat-health indicator able to define and recognize heat stress conditions responsible for the mortality burden associated with heat waves, and 2) to assess the relative advantage of using a bioclimatological index for heat-health warning systems with respect to single variables, that is, air temperature. Using France as a test bed, UTCI-based gridded information has been computed over the area 


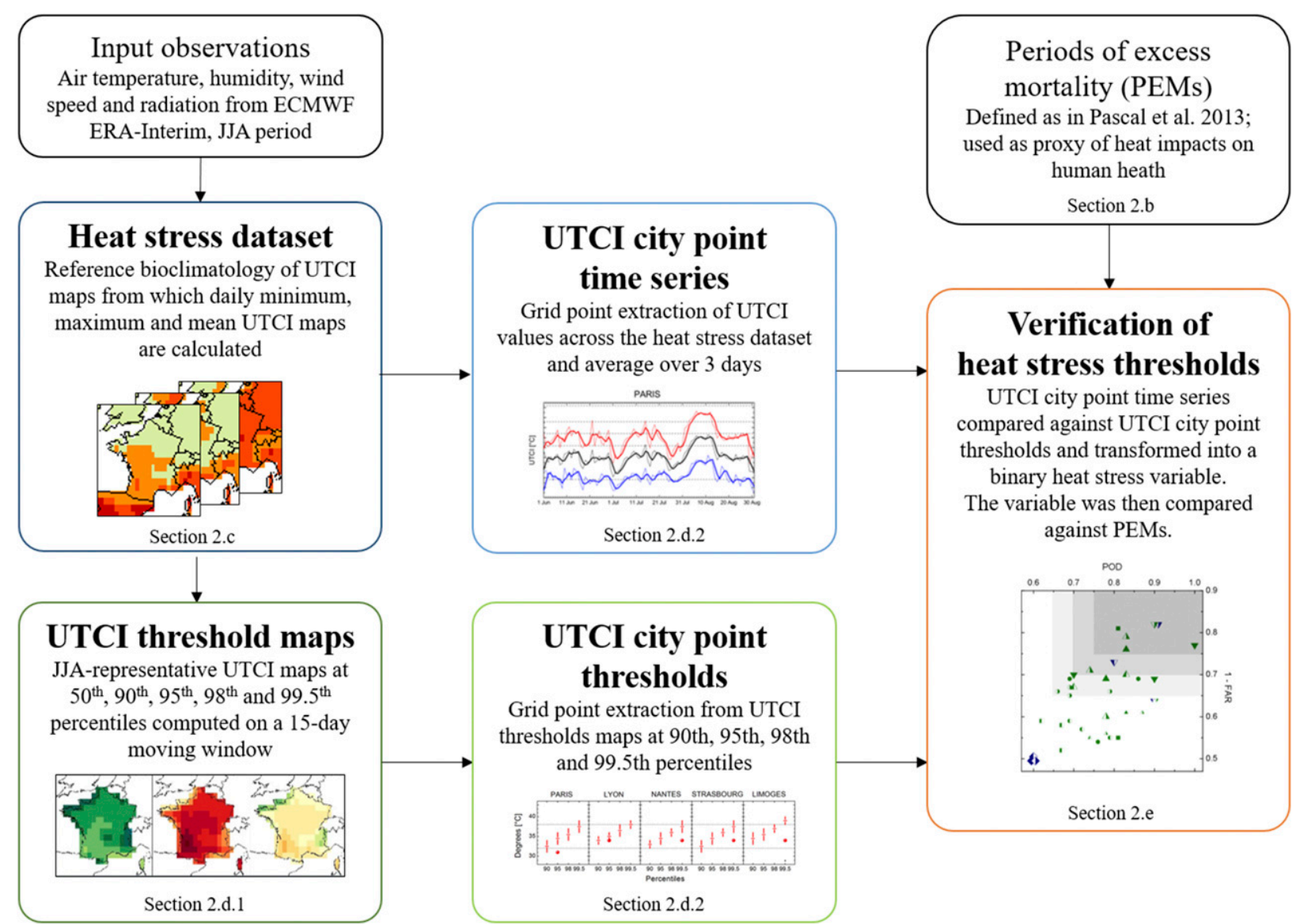

FIG. 1. Flowchart describing the datasets and methods used in the study.

from the European Centre for Medium-Range Weather Forecasts (ECMWF) reanalysis data. In five different major French cities, UTCI bioclimatology has been extrapolated and investigated in heat-wave and nonheat-wave conditions. From there UTCI thresholds have been calculated at different percentiles and tested using verification metrics in their ability to identify days when excess mortality due to heat has been observed.

\section{Data and methods}

This study focuses on France both at the national and at the city level. At the city level, five regional capitals were considered, namely, Paris, Lyon, Nantes, Strasbourg, and Limoges, which are representative of different geographical areas and population sizes [from 130000 to 2200000 inhabitants; the National Institute of Statistics and Economic Studies (Institut National de la Statistique et des Études Économiques); Insee (2018)]. The analysis considers the summer season from 1 June to 31 August (JJA), as major European heat waves occurred in this period (Russo et al. 2015). Figure 1 provides an overview of the datasets and methods described in the present section.

\section{a. Health data}

Health impacts of excessive heat cover a wide range of sectors and are generally quantified via different metrics. These are based either on morbidity (as measured by increased hospital admissions; Semenza et al. 1999) or on mortality (Sheridan and Kalkstein 2004). Health-meaningful thresholds for a HHWWS are usually determined from mortality data. Whereas reports on morbidity depend on guidelines set by national health systems and may therefore vary from country to country, mortality data are more standardized (McGregor et al. 2015). The French HHWWS is based on 31 years of mortality data (1973-2003, August 2003 excluded; Pascal et al. 2013). Furthermore, it builds on the analysis of daily deaths from any cause as reported from Insee (Pascal et al. 2013). The number of deaths that according to the official definition are identified as "heat-related deaths," that is, due directly or significantly to heat, underestimates the 
actual impact of heat, which is known to have a potential contributing role also toward cardiovascular and respiratory deaths (Donoghue et al. 1997; McGregor et al. 2015). In line with this the present study focuses on allcause mortality data.

\section{b. Periods of excess mortality}

To quantify the mortality attributable to heat, an "excess mortality" has to be estimated by subtracting the expected mortality from the observed mortality (Gosling et al. 2009). The expected mortality or "baseline" is a normal daily value, standardized to account for demographic changes over time, to which long-term mortality data are reduced (Sheridan and Kalkstein 2004). From this baseline, daily heat-attributable excess mortality can be estimated and correlated with environmental conditions. Different methods have been applied to calculate expected and excess mortality (Gosling et al. 2009). One method is the epidemiological approach, which explains excess mortality based upon one or more predictors, such as air temperature, air pollution and other environmental variables (Basu and Samet 2002).

Two main epidemiological-based approaches have been described in the scientific literature to assess excess mortality in France as the short-term impact of heat waves on human health. In the first approach the excess mortality is evaluated on the days when a given meteorological parameter, such as $2-\mathrm{m}$ air temperature, exceeds specific thresholds (Antics et al. 2013). In the second approach the excess mortality is defined over periods when the number of deaths exceeds a baseline equal to the mean of mortality observed in the period between 1973 and 2003 (August 2003 excluded for the atypical mortality response) plus three standard deviations $(\sim 99.7$ th percentile, Pascal et al. 2013). When death counts exceed the reference baseline for 3 consecutive days or longer, a period of excess mortality (PEM) is identified. PEMs represent an ideal benchmark for the characterization of heat stress in heat-wave events with proven effects on health. The reason is twofold. First, the mortality baseline does not include years when the French HHWWS started to be operational and could potentially modify the original heat-health relationship. Second, differently from the days considered with the first method, PEMs are defined independently from meteorological conditions. PEMs have been recently used by Pascal et al. (2013) to improve the French HHWWS first described by the same team in 2006 (Pascal et al. 2006). In line with this, the present study considers the all-cause all-age PEMs reported in Pascal et al. (2013) for Paris, Lyon, Nantes, Strasbourg, and Limoges (Table 1).
TABLE 1. Periods of excess mortality (PEMs) for the cities considered in the study. PEMs are as defined in Pascal et al. (2013). For each PEM the duration is indicated by a number in the square brackets.

\begin{tabular}{lll}
\hline \multicolumn{1}{c}{ City } & Year & \multicolumn{1}{c}{ PEMs } \\
\hline Paris & 1990 & 3-5 Aug [3] \\
& 1995 & 2-4 Aug [3] \\
& 1998 & 9-12 Aug [4] \\
& 2003 & 4-14 Aug [11] \\
Lyon & 1983 & 21 Jul-1 Aug [12] \\
& 1998 & 10-12 Aug [3] \\
& 2003 & 23-25 Jun [3] \\
& & 4-14 Aug [11] \\
Nantes & 1983 & 10-15 Jul [6] \\
& 1990 & 22-23 Jul [2] \\
& & 2-5 Aug [4] \\
& 2003 & 4-14 Aug [11] \\
Strasbourg & 2003 & $5-14$ Aug [10] \\
Limoges & 2003 & 3-7 Aug [5] \\
\hline
\end{tabular}

\section{c. Heat stress dataset}

The UTCI is the air temperature of the reference condition that would cause in the human body the same physiological response (rectal, mean skin, and facial skin temperatures, sweat production, skin wettedness, skin blood flow, shivering) as the real condition. The reference condition is represented by an average individual walking at $4 \mathrm{~km} \mathrm{~h}^{-1}$ in a state of calm air (wind speed $0.5 \mathrm{~m} \mathrm{~s}^{-1}$ at $10 \mathrm{~m}$ above the ground), no additional thermal irradiation and 50\% relative humidity (capped at $2 \mathrm{kPa}$ for air temperatures above $29^{\circ} \mathrm{C}$ ). The difference between the UTCI and the air temperature of the real condition $T_{a}$ depends on the actual values of $T_{a}$, solar and thermal radiation (expressed as mean radiant temperature $T_{\mathrm{mrt}}$ ), wind speed (va), and humidity, with the latter defined in terms of water vapor pressure (vp) or relative humidity (RH) (Błażejczyk et al. 2013).

UTCI is theoretically valid across the entire range of thermal exposure, that is, from cold to heat, and it is classified into a 10-category scale. Each category, defined by a specific range of UTCI values, corresponds to a well-defined set of human physiological responses to the outdoor environment, which can be controlled and/or prevented by adopting different behaviors and clothing styles (Błażejczyk et al. 2010a, 2013). As this study focuses on the health impacts of heat waves, five thermal stress categories, ranging from slight cold stress to very strong heat stress, are considered (Table 2).

UTCI bioclimatology, that is, the long-term occurrence of heat stress categories, for France was computed using ERA-Interim dataset (Dee et al. 2011). ERA-Interim gridded data of 2-m air temperature, 2-m dewpoint temperature, $10-\mathrm{m}$ wind speed, and thermal and solar radiation were used as proxy for observations 
TABLE 2. UTCI assessment scale of thermal stress, corresponding physiological responses and possible protection measures [adapted from Błażejczyk et al. (2010a) and Błażejczyk et al. (2013)].

\begin{tabular}{|c|c|c|c|}
\hline UTCI range $\left[{ }^{\circ} \mathrm{C}\right]$ & Stress category & Physiological responses & Protection measures \\
\hline Above +46 & Extreme heat stress & $\begin{array}{l}\text { Increase in rectal temperature time } \\
\text { gradient. Steep decrease in total net } \\
\text { heat loss. Averaged sweat rate } \\
>650 \mathrm{~g} \mathrm{~h}^{-1}, \text { steep increase. }\end{array}$ & $\begin{array}{l}\text { Temporary body cooling and drinking } \\
>0.5 \mathrm{~L} \mathrm{~h}^{-1} \text { necessary. } \\
\text { No physical activity. }\end{array}$ \\
\hline+38 to +46 & Very strong heat stress & $\begin{array}{l}\text { Low core-skin temperature gradient. } \\
\text { Increase in rectal temperature at } \\
30 \text { min. }\end{array}$ & $\begin{array}{l}\text { Temporary use of air condition. Shaded } \\
\text { places necessary. Drinking }>0.5 \mathrm{Lh}^{-1} \text {. } \\
\text { Reduce physical activity. }\end{array}$ \\
\hline+32 to +38 & Strong heat stress & $\begin{array}{l}\text { Averaged sweat rate }>200 \mathrm{~g} \mathrm{~h}^{-1} \text {. Increase } \\
\text { in rectal temperature at } 120 \mathrm{~min} . \\
\text { Instantaneous change in skin } \\
\text { temperature. }\end{array}$ & $\begin{array}{l}\text { Use shaded places. } \\
\text { Drinking }>0.25 \mathrm{~L} \mathrm{~h}^{-1} \text {. Temporary reduce } \\
\text { physical activity. }\end{array}$ \\
\hline+26 to +32 & Moderate heat stress & $\begin{array}{l}\text { Change of slopes in sweat rate and rectal } \\
\text { and skin (mean, face, hand) } \\
\text { temperature. Occurrence of sweating at } \\
30 \text { min. Steep increase in skin } \\
\text { wettedness. }\end{array}$ & Drinking $>0.25 \mathrm{~L} \mathrm{~h}^{-1}$. \\
\hline+9 to +26 & No thermal stress & $\begin{array}{l}\text { Averaged sweat rate }>100 \mathrm{~g} \mathrm{~h}^{-1} \text {. Plateau } \\
\text { in rectal temperature time gradient. }\end{array}$ & $\begin{array}{l}\text { Physiological thermoregulation sufficient } \\
\text { to keep thermal comfort }\end{array}$ \\
\hline 0 to +9 & Slight cold stress & Local minimum of hand skin temperature. & Use gloves and hat. \\
\hline-13 to 0 & Moderate cold stress & $\begin{array}{l}\text { Vasoconstriction. Face skin temperature } \\
\text { at } 30 \mathrm{~min}<15^{\circ} \mathrm{C} \text { (pain). }\end{array}$ & $\begin{array}{l}\text { Intensify activity and protect face and } \\
\text { extremities against cooling. }\end{array}$ \\
\hline-13 to -27 & Strong cold stress & $\begin{array}{l}\text { Numbness. Increase in core-skin } \\
\text { temperature gradient. }\end{array}$ & $\begin{array}{l}\text { Intensify activity and protect face and } \\
\text { extremities against cooling. Use } \\
\text { warmer clothing. }\end{array}$ \\
\hline-27 to -40 & Very strong cold stress & $\begin{array}{l}\text { Frostbite, numbness, shivering. Steeper } \\
\text { decrease in rectal temperature. }\end{array}$ & $\begin{array}{l}\text { Intensify activity and protect face and } \\
\text { extremities against cooling. Use } \\
\text { warmer clothing. Reduce outdoor } \\
\text { exposure time. }\end{array}$ \\
\hline Below -40 & Extreme cold stress & $\begin{array}{l}\text { Frostbite. Decrease in rectal temperature } \\
\text { time gradient. }\end{array}$ & $\begin{array}{l}\text { Stay at home. If outdoor exposure is } \\
\text { necessary, use heavy and wind } \\
\text { protected clothing. }\end{array}$ \\
\hline
\end{tabular}

of the environmental parameters $T_{a}, T_{\mathrm{mrt}}$, va, and RH (Simmons et al. 2010; Dee et al. 2011; Mooney et al. 2011; Szczypta et al. 2011; Haiden et al. 2018). ERAInterim data were input to the UTCI operational procedure, which consists of calculating the offset between the UTCI and $T_{a}$ via a six-order polynomial equation in $T_{a}, T_{\mathrm{mrt}}$, va, and RH (Bröde et al. 2012). Applying the UTCI operational procedure is less computationally intensive and time-consuming than solving the original UTCI-Fiala model, and it is therefore more suitable to the calculation of long historical UTCI datasets (e.g., in Di Napoli et al. 2018).

From 1 June to 31 August, the UTCI operational code was applied to ERA-Interim environmental parameters retrieved at 3-h time steps, that is, at 0300, 0600, 0900, $1200,1500,1800,2100$, and 2400 coordinated universal time (UTC). The output is a set of eight UTCI maps at the France scale with a spatial resolution of approximately $80 \mathrm{~km}$ (the same as ERA-Interim) for each summer day. The daily UTCI-based heat stress dataset so obtained covers a period similar to that used to define PEMs. It starts from 1979, the first available year from the ERA-Interim dataset, and ends on 2002. The 2003 JJA period has been excluded because periods of exceptional heat occurred throughout, creating a state of exhaustion in vulnerable people that culminated in 15000 excess deaths (Fouillet et al. 2006; Pascal et al. 2006; García-Herrera et al. 2010).

From the 1979-2002 heat stress dataset, daily minimum and maximum UTCI values were extracted within a 24-h cycle (0000-2100 UTC) for each grid point in the France domain. Mean daily UTCI values were calculated by averaging corresponding daily UTCI minima and maxima.

\section{d. Definition of heat stress thresholds}

\section{1) UTCI THRESHOLD MAPS}

Daily minimum, maximum, and mean UTCI values were used to calculate UTCI maps at the 90th, 95th, 98th, and 99.5th percentiles (80-km spatial resolution). The choice of these percentiles is justified by their historical use within the heat-wave research field. High and very high percentiles are employed in impact studies of heat waves on mortality (Xu et al. 2016). The 95th, 98th, 
TABLE 3. Contingency table for the verification of UTCI thresholds in identifying periods with observed heat-attributable excess mortality.

\begin{tabular}{lllll}
\hline \hline & & \multicolumn{2}{c}{ PEM? } \\
\cline { 3 - 3 } & & \multicolumn{1}{c}{ YES } & B \\
\hline UTCI value above percentile threshold? & YES & A (hit) & B (false alarms) & A + B \\
& NO & C (miss) & D (correct rejection) & C + D \\
& & A + C & B + D & A + B + C + D \\
\hline
\end{tabular}

and 99.5th percentiles, for instance, have been previously investigated as associated with excess deaths and in general to negative health effects from extreme air temperatures in France (Pascal et al. 2006, 2013). The choice of the 99.5th percentile is also in line with the three-standard-deviation range ( $\sim 99.7$ th percentile) used in the definition of PEMs. The 90th and 95th percentiles are commonly adopted as thresholds in the definition and identification of heatwave events against non-heat-wave events (Perkins and Alexander 2013). For this study, UTCI maps corresponding to the 50th percentile (i.e., the median) were also calculated as representative of the summer French bioclimate.

UTCI percentile maps are computed on a 15-day moving window. For each calendar day, daily maximum (minimum or mean) UTCI values were extracted at each grid cell for that same day, the 7 days before, and the 7 days after, and correspondingly from all the other years of the 1979-2002 period. From the sample of maximum (minimum or mean) UTCI values so collected, the 50th, 90th, 95th, 98th, and 99.5th percentiles were calculated and 92 maximum (minimum or mean) UTCI maps obtained for each percentile. The reason for choosing a moving window is twofold. First, it takes into account the UTCI temporal variation across the summer season, that is, every grid point has a different percentile value for each day the calculation window is centered. Second, it removes possible artifacts due to the reduced dataset (24 years) as it calculates percentile values from a larger sample size at each day. The duration of the moving window has been set to 15 days in agreement with previous literature on heat waves (e.g., Fischer and Schär 2010).

For a given percentile the 92 maximum (minimum or mean) UTCI maps were then averaged together to obtain one maximum (minimum or mean) UTCI threshold map at the scale of France. This is in order to define UTCI thresholds that can be considered representative of the whole JJA season and in consistency with the 2-m air temperature thresholds currently adopted in the French HHWWS (Pascal et al. 2013).

\section{2) UTCI CITY POINT THRESHOLDS}

At the city scale, nearest grid points corresponding to the locations of Paris, Lyon, Nantes, Strasbourg, and
Limoges were selected. For each point, that is, for each city, thresholds at the 90th, 95th, 98th and 99.5th percentiles were extracted from corresponding UTCI threshold maps. Time series of daily maximum, minimum and mean UTCI values were extrapolated from the heat stress dataset and averaged over a 3-day moving window. This is in order to take into account the cumulative effect of heat stress overtime. Given a day $d$ characterized by elevated heat stress, for instance, conditions of lower heat stress on days $d-1$ and $d-2$ may reduce the overall heat load across the 3-day window, and therefore impact human health differently than a 3-day period with all days at high heat stress levels.

\section{e. Verification of heat stress thresholds}

To quantify the performance of the UTCI as an indicator of PEMs in the five cities considered in the study, the day to day occurrence of heat stress conditions was transformed into a dichotomous event according to the UTCI city point thresholds defined in the previous section. Specifically, a binary heat stress variable ( 1 or 0 ) was defined and computed. For a given city, the binary heat stress variable was set equal to 1 when the daily 3-day-averaged UTCI maximum value was above the corresponding UTCI threshold at 90th percentile, and 0 otherwise. The value was also compared to the 95th, 98th, and 99.5th percentiles, and binary heat stress variables defined accordingly. The procedure was also applied to daily 3-day-averaged UTCI minimum and mean value, and combinations of minimum and maximum UTCI values.

For each day, the binary heat stress variable was then compared against PEMs, here used as proxy for observations of heat-health impacts. We defined hit when the binary heat stress variable is 1 within a PEM, miss when it is 0 within a PEM, false alarm when it is 1 in a day that does not belong to a PEM, and correct rejections when it is 0 in a day that does not belong to a PEM. Obtained counts are summarized in a contingency table (Table 3 ). Correct rejections are roughly two orders of magnitude higher than the other three fields. This is because PEMs are rare events. The number of days characterized by heat-wave-induced excess mortality are less than $1.4 \%$ 
of the total number of JJA days in the study period. Counts of correct rejections were therefore not considered and UTCI thresholds for a health-based heatwave definition were tested using verification metrics based on counts of hits, misses and false alarms (Ferro and Stephenson 2012). Chosen metrics were the probability of detection (POD), the false alarm ratio (FAR) and the frequency bias (FB). These have been extensively used in literature to evaluate predictability performances for different heat-wave definitions or heat-wave-related impacts (Pascal et al. 2013; Richman and Leslie 2014; Watkins 2014; Wolf et al. 2014; Lowe et al. 2015). On the operational side, they are adopted by weather services, such as the Met Office and ECMWF, to routinely verify warnings (Gordon and Shaykewich 2000; Magnusson et al. 2014; Sharpe et al. 2018). Scores were calculated over the summer period (JJA; 1979-2003) as follows:

$$
\begin{array}{ll}
\mathrm{POD}=\text { hits } /(\text { hits }+ \text { misses }), & \text { range: }[0,1], \text { best: } 1 \\
\mathrm{FAR}=\text { false alarms } /(\text { hits }+ \text { false alarms }), & \text { range: }[0,1], \text { best: } 0 \\
\mathrm{FB}=(\text { hits }+ \text { false alarms }) /(\text { hits }+ \text { misses }), & \text { range: }[0,+\infty], \text { best: } 1
\end{array},
$$

where POD is the fraction of PEMs correctly identified using a given UTCI threshold; FAR is the fraction of days with heat stress above the UTCI threshold that are not defined as PEMs; FB indicates whether the UTCI threshold has a tendency to identify less $(\mathrm{FB}<1)$ or more $(\mathrm{FB}>1)$ days than those defined as PEMs. Furthermore, given the potential detrimental health impacts associated with the cumulative effect of heat stress, UTCI thresholds were also verified in duration, that is, the number of days $(1,2$, or 3$)$ they need to be exceeded for in order to have the observed PEM.

A health-impact heat-wave indicator performs best, and can therefore be considered suitable for heathealth hazard forecasting in a HHWWS, when it has sensitivity and specificity, that is, it correctly identifies the highest number of days with heat-attributable mortality (sensitivity) while minimizing false and missed alarms (specificity; Kovats and Ebi 2006). A high number of days wrongly predicted as PEMs or not correctly forecast as such could undermine the credibility of the HHWWS. Furthermore, decision makers may place excessive emphasis on false warnings and underestimate the correct ones, especially when the latter are not followed by significant health impacts (Pascal et al. 2013). UTCI thresholds associated with the following three criteria-high POD $(0.5 \leq$ POD $\leq 1)$ and low FAR $(\leq 0.5)$ and FB close to $1(1 \leq \mathrm{FB} \leq 1.5)$-were therefore adopted.

\section{f. Performance comparison of heat stress thresholds with air temperature thresholds}

UTCI thresholds were compared with air temperature thresholds currently adopted by the French HHWWS in the regional cities considered in the study. The performance of air temperature thresholds is reported by Pascal et al. (2013) in terms of three indicators:
Percentage of correct alarms $=$ hits $/($ hits + false alarms $) \times 100$,
range: $[0,100]$, best: 100
Percentage of false alarms $=$ false alarms $/($ hits + false alarms $) \times 100$,
Percentage of missed alarms $=$ misses $/($ hits + misses $) \times 100$,
range: $[0,100]$, best: 0
range: $[0,100]$, best: 0

Note that the percentage of false alarms is FAR multiplied by 100 . For consistency, the same indicators were computed for UTCI thresholds with the highest sensitivity and specificity.

\section{Results}

\section{a. Bioclimatology of study area and cities}

UTCI maps derived from the 1979-2002 ERAInterim data (50th percentile) show the summer thermal bioclimate of France is characterized by a specific time and spatial variability (Fig. 2a). Daily maximum UTCI values indicate conditions of no thermal stress in the north-northwest that increase to moderate heat stress levels toward the south. Daily minimum UTCI values follow a similar pattern with northern regions characterized by slight cold stress conditions and southern regions experiencing no thermal stress. These two trends contribute toward daily mean UTCI values in the no thermal stress category across the whole France. The variation in space of the UTCI reflects the two KöppenGeiger climates characterizing the study area (Peel et al. 2007)_oceanic climate at higher latitudes, Mediterranean climate at lower latitudes. It also correctly captures changes in the thermal bioclimate due to the local geography and orography. In the southern part of France, for instance, 
(a)

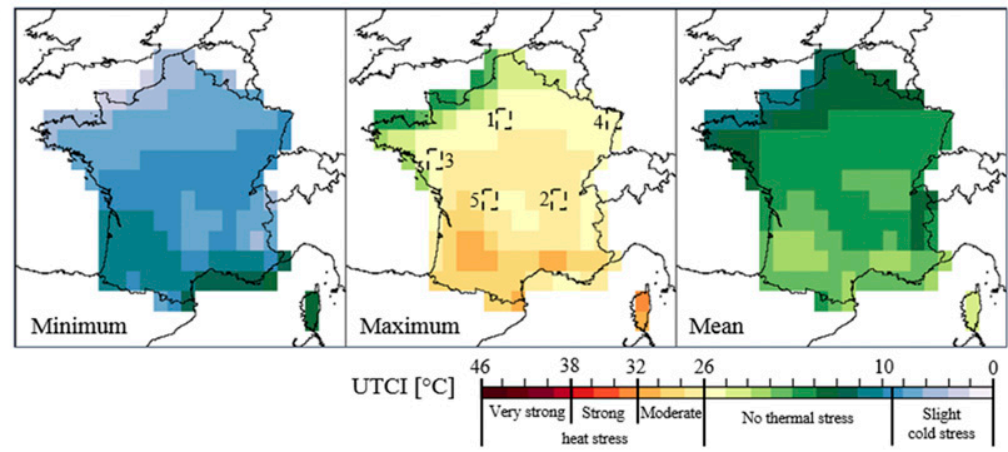

(b)

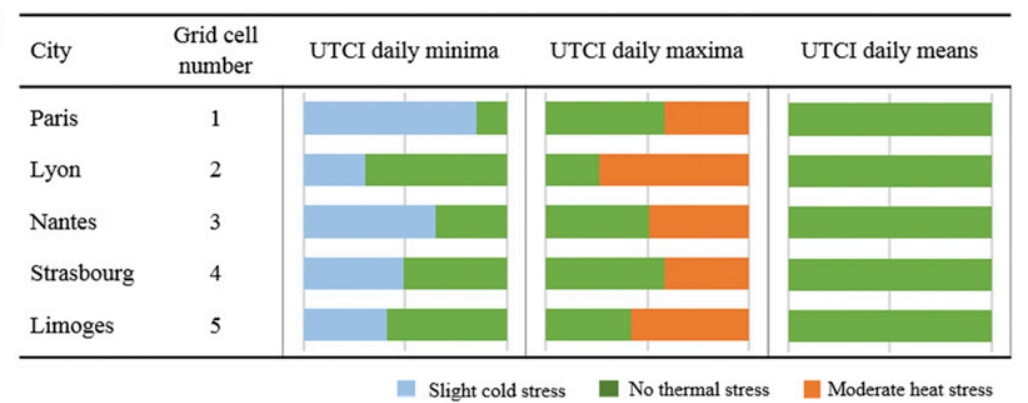

(c)

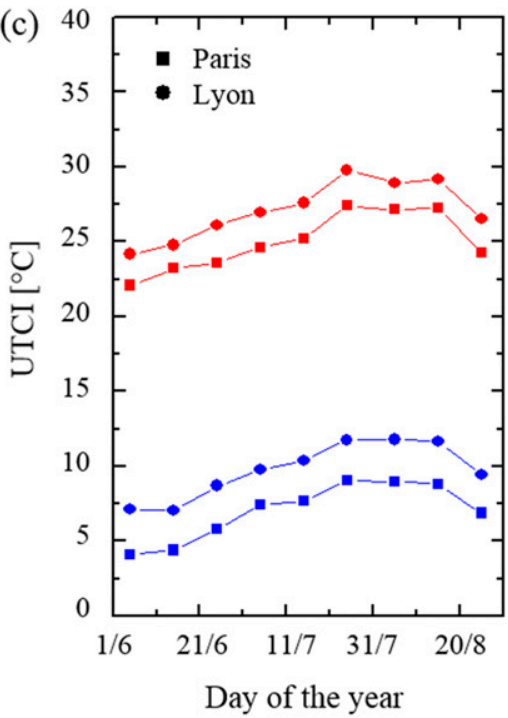

Day of the year

FIG. 2. Thermal bioclimatology of France and five main cities in the JJA period. (a) Maps showing the daily (left) minimum, (center) maximum, and (right) mean UTCI values across France as computed from 1979-2002 ERA-Interim data (50th percentile). (b) Frequency of occurrence of UTCI stress categories as computed for Paris, Lyon, Nantes, Strasbourg, and Limoges from the same dataset. City locations are indicated in (a) by corresponding gridcell numbers. (c) Intraseasonal trends of UTCI daily minima (blue) and maxima (red) for Paris and Lyon. Points refer to 10-day means.

mountainous areas such as the Alps, the Massif Central, and the Pyrenees experience decreased thermal stress than areas at lower altitude like the Aquitaine basin and the Rhône valley.

The thermal bioclimatic plots of the five cities considered in the study show that the frequency of occurrence of UTCI categories across the JJA season, and therefore the local human adaptation to heat stress, also depends on the climate (Fig. 2b). While UTCI daily means indicate average conditions of no thermal stress, UTCI daily minima and maxima provide a more detailed insight into the bioclimate of selected cities. For at least $51 \%$ of the JJA period, Paris, Nantes, and Strasbourg experience slight cold stress and no thermal stress, respectively. Lyon and Limoges, on the contrary, undergo more frequent conditions of no thermal stress and moderate heat stress in their daily minima and maxima. All five cities are located in areas associated with a warm-summer temperate oceanic climate (Cfb) (Peel et al. 2007). However, local topography is responsible for deviations in the climate of Limoges and Lyon, with the latter for instance displaying characteristics similar to continental climate (Auffray et al. 2012; Laaidi et al. 2006).

This is reflected also in the intraseasonal trend of heat stress (Fig. 2c). UTCI daily minima and maxima averaged over a 10-day window are higher for Lyon than for Paris. In both cities, however, the trend over the JJA season is similar. The UTCI increases and reaches a peak around the last 10 days of July and it stays at approximately at the same value for the first 20 days of August, after which it decreases. This suggest an adaptation to elevated heat stress levels when these occur in the second part of the summer and a potential vulnerability of the local population when severe heat events take place in the first part of the summer instead.

\section{b. UTCI thresholds for heat-wave-induced health impacts}

The different bioclimates of Paris, Lyon, Nantes, Strasbourg, and Limoges are reflected in the values of the UTCI city point thresholds at the 90th, 95th, 98th, and 99.5 percentiles computed from the heat stress dataset (Fig. 3).

Maximum UTCI city point thresholds are mainly in the strong heat stress category with 90th-percentile values higher for Lyon and Limoges, and 99.5thpercentiles values extending to the very strong heat stress category in all five cities. This result suggests that there is a $10 \%$ probability over the JJA period to have conditions associated with maximum UTCI values equal 


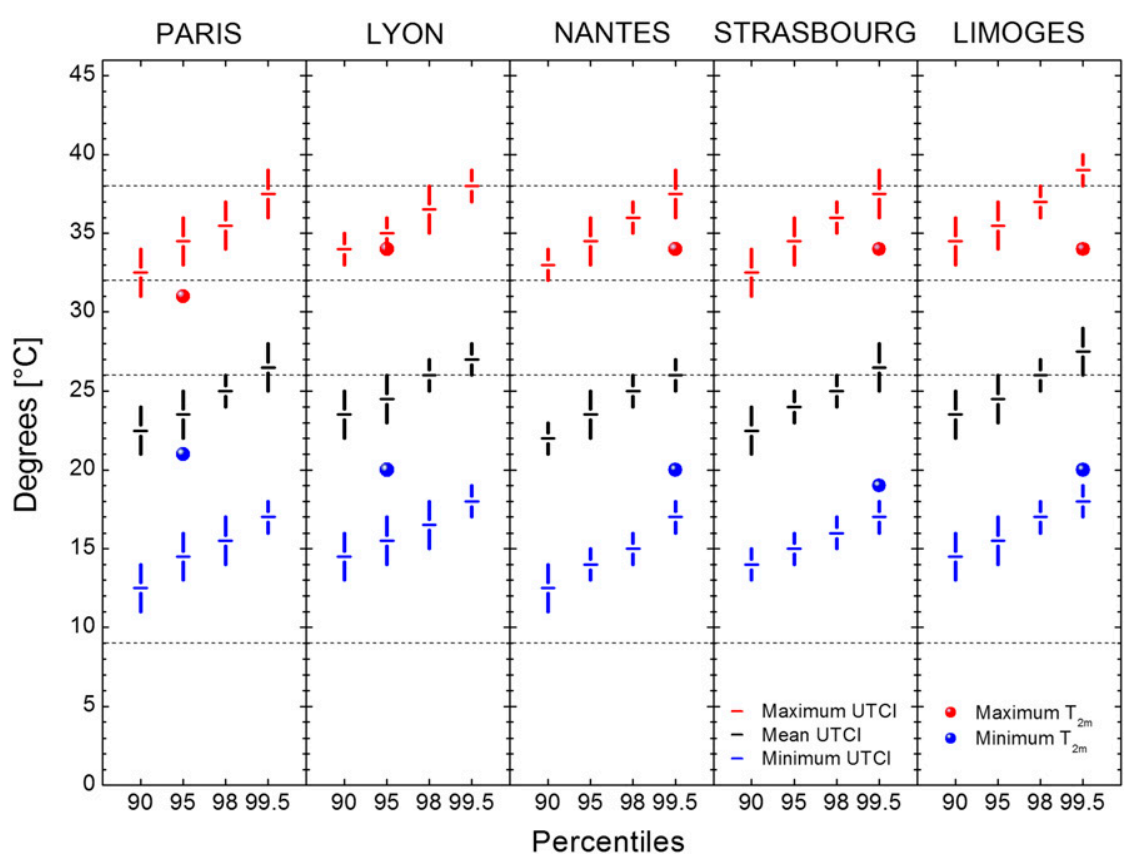

FIG. 3. UTCI and 2-m air temperature values associated with the 90th, 95th, 98th, and 99.5th percentiles in selected cities. Maximum and minimum 2-m air temperature values (red and blue dots, respectively) are as in Pascal et al. (2013). Corresponding UTCI values are computed from the climatological 1979-2002 period (red and blue lines, respectively, and mean in black). Error bars represent the variability of values in the JJA season. Dashed lines delimitate UTCI stress categories.

or above $32^{\circ} \mathrm{C}$, and $0.5 \%$ probability that conditions get close or above $38^{\circ} \mathrm{C}$. Events characterized by strong and very strong heat stress in their UTCI maxima therefore expose the local population to a heat load higher than the one they are adapted to, with potential negative consequences to their health.

Minimum UTCI city point thresholds are in the "no thermal stress" category. Average values are between $11^{\circ}$ and $18^{\circ} \mathrm{C}$ for Paris and Nantes, between $13^{\circ}$ and $18^{\circ} \mathrm{C}$ for Strasbourg, and between $13^{\circ}$ and $19^{\circ} \mathrm{C}$ for Lyon and Limoges. The combination with maximum UTCI city point thresholds generates mean UTCI thresholds at the intersection between the no thermal stress and the moderate heat stress categories. Mean UTCI city point thresholds associated with the 98th and 99.5th percentiles are close or above $26^{\circ} \mathrm{C}$, making this value potentially impact meaningful.

In Fig. 3, the maximum and minimum thresholds currently employed in the French HHWWS are also shown (Wagner et al. 2018). The thresholds, based on 2-m air temperature only, generally differ from the corresponding UTCI city point thresholds as their values are outside the variability range of UTCI city thresholds (a statistical-based comparison can be found in the online supplemental material). This is due to the dependency of the UTCI on other meteorological parameters that, together with air temperature, are used to define the environmental conditions affecting the human thermal energy balance. Although it has some linear dependencies on air temperature, the UTCI is very sensitive also to changes in humidity, wind speed, and radiation (Błażejczyk et al. 2012; Pappenberger et al. 2015). Maximum UTCI city point thresholds, for instance, are in general greater than corresponding air temperature percentiles, indicating a potential contribution toward higher heat stress levels from other meteorological parameters.

\section{c. Biometeorological conditions associated with PEMs}

Comparing UTCI time series with the PEMs identified by Pascal et al. 2013 provides further insights to the relationship between UTCI, heat stress and health impacts in the five cities considered in the study (Fig. 4).

PEMs are characterized by different duration (Table 1). The longest PEMs are associated with the prolonged and intense heat wave that hit Europe in summer 2003 and exacerbated heat stress well above climatological and adaptation levels (Di Napoli et al. 2018). France was one of the countries where the 2003 European heat wave was responsible for a major increase in heat-related mortality (Fouillet et al. 2006). The values reached during August 
PARIS

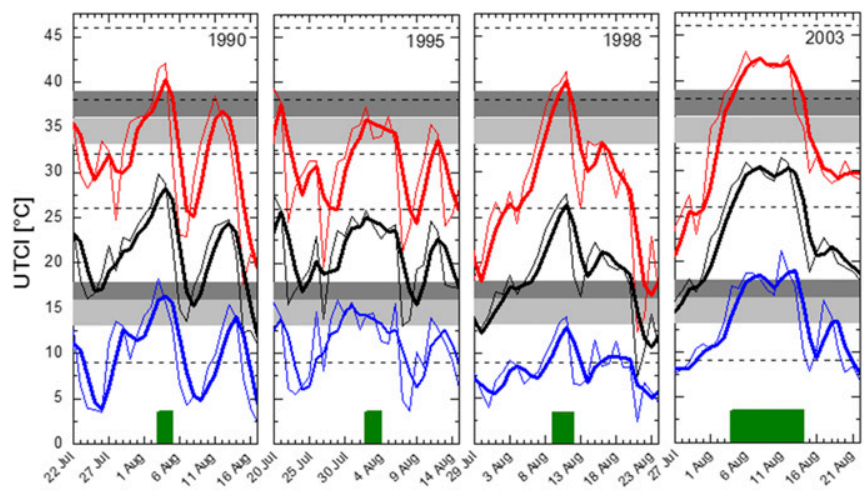

NANTES
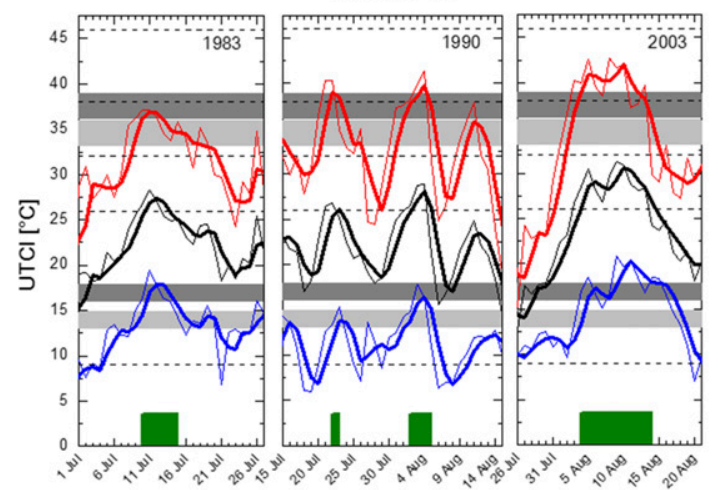
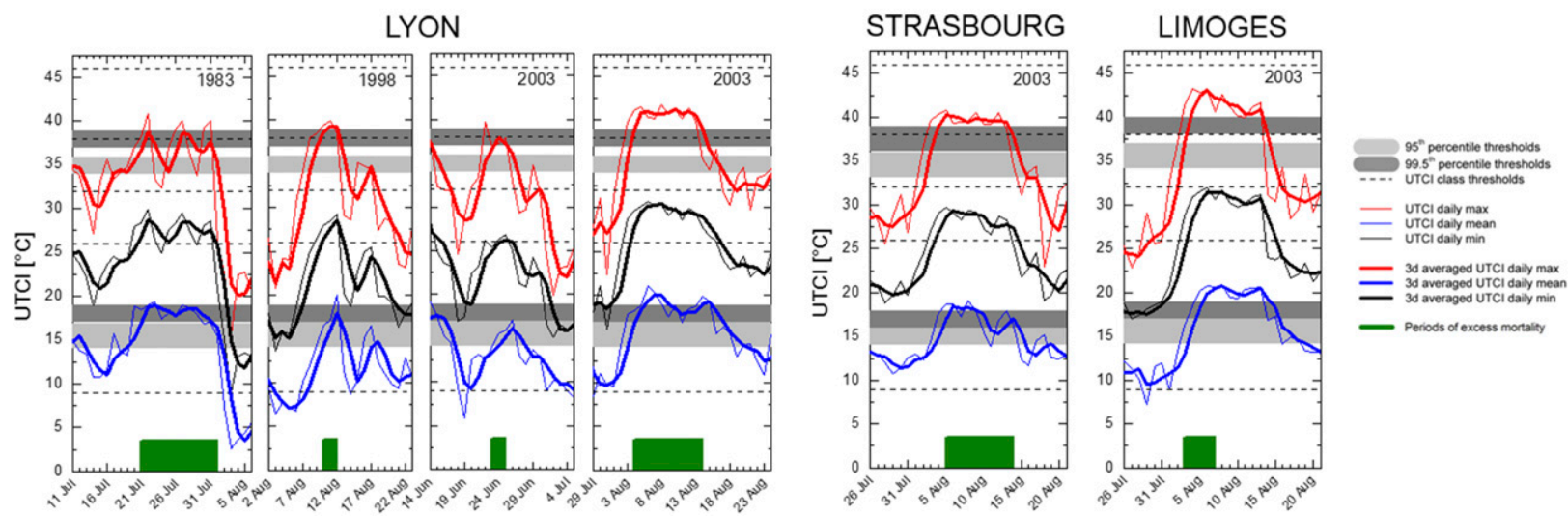

FIG. 4. Time series of minimum (blue), mean (black), and maximum (red) UTCI values during events characterized by heat-induced excess mortality in the five cities investigated in the study. UTCI values are represented as both daily and 3-day-averaged data. Bands corresponding to the 95th and 99.5th percentiles of the 1979-2002 UTCI climatological period are shown for comparison. Dashed lines delimitate UTCI stress categories.

2003 in the UTCI city point time series confirm the extreme environmental conditions achieved in the five study capitals during that period. Maximum UTCI values increased to $38^{\circ} \mathrm{C}$ or more (very strong heat stress), and above the 99.5th percentile. Minimum UTCI values were also close or above the corresponding 99.5th percentile as were the mean UTCI values, with the latter between $26^{\circ}$ and $32^{\circ} \mathrm{C}$ (moderate heat stress). These levels of uncommon, aggravated heat stress characterized the dayand nighttime bioclimatology of Paris, Nantes, Lyon, Strasbourg, and Limoges for more than 10 days.

UTCI values close to the highest percentiles were achieved for a prolonged period also during the heat wave that hit France in July 1983, especially the southeast (Lemonsu et al. 2014). Lyon was one of the affected cities. While maximum UTCI values oscillated between the 95 th and the 99.5 th percentiles, minimum UTCI values were closer to the 99.5th percentile suggesting a nonnegligible contribution to heat stress from nighttime. This is in agreement with epidemiological studies based on air temperature that associated excess mortality in the area with elevated nighttime temperatures (Simonet 1985; Murage et al. 2017).

Shorter, less intense heat waves occurred in 1990, 1995, and 1998 that also had an impact on mortality (Rey et al. 2007; Le Roy Ladurie and Rousseau 2009; Lemonsu et al. 2014). In Paris, Nantes, and Lyon the 95th and 99.5th percentiles were achieved or exceeded by maximum, mean and minimum UTCI values still indicating a role for heat stress as health hazard.

To quantitatively determine which heat stress conditions are associated with health impacts, the skill of UTCI climatological values at 90th, 95th, 98th, and 99.5th percentiles in identifying PEMs have been assessed for each study city via verification metrics (Fig. 1).

\section{d. Verification of UTCI thresholds for a health-based heat-wave definition}

The performance of UTCI as PEM-associated indicator was evaluated for different combinations of UTCI city point thresholds, namely, minimum, maximum, mean, and minimum-maximum. Results are summarized in Fig. 5 for all the five cities (complete set of 


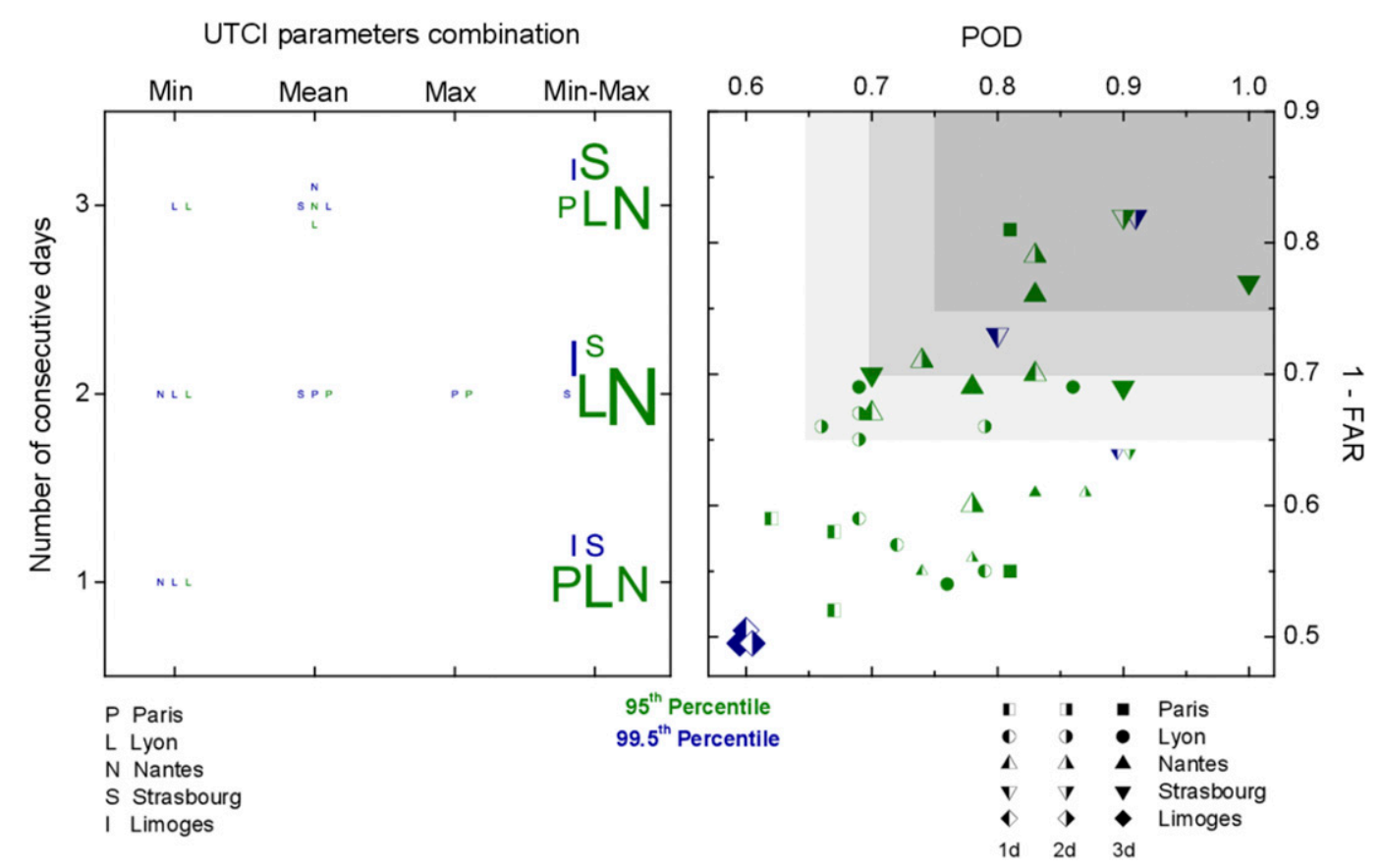

FIG. 5. Performance of UTCI as a PEM-associated indicator in study cities for different combinations of UTCI climatological values at the 95th and 99.5th percentiles, namely, minimum, mean, maximum, and minimummaximum. (left) The occurrence of each combination is presented for 1, 2, and 3 consecutive days, and it is proportional to the letter size of the corresponding city (absolute numbers can be found in the supplemental material). (right) The skills of the minimum-maximum UTCI combination in successfully identifying PEMs are represented in terms of probability of detection (POD) and false alarm ratio (FAR), with the latter expressed as 1 - FAR in order to be on the same [0,1] scale as POD. Symbol size is proportional to the inverse of the frequency bias (FB), i.e., the bigger the size, the lower the FB. Dark gray, gray, and light gray areas are indicative of POD and 1 - FAR greater than or to $0.75,0.70$, and 0.65 respectively. A complete set of results can be found in the supplemental material.

verification scores can be found in the supplemental material).

Among the most skillful indicators $(0.5 \leq \mathrm{POD} \leq 1$, FAR $\leq 0.5$, and $1 \leq \mathrm{FB} \leq 1.5)$, the combination of minimum-maximum thresholds appears most frequently in all cities (Fig. 5, left panel). The thresholds correspond to the minimum and maximum UTCI values at the 95th percentile in Paris, Lyon, and Nantes; at the 95th and 99.5th percentiles in Strasbourg, and at the 99.5th percentile in Limoges. The 99.5th percentile appears as heat-health indicator in Strasbourg and Limoges because only one PEM has been identified for those two cities, and that PEM occurred during the extreme 2003 European heat wave, specifically in the month of August, when the heat stress and related UTCI values were at their highest. This result confirms the importance of considering minimum as well as maximum thresholds in the assessment of heat-health impacts rather than minimum or maximum thresholds alone. Although a similar outcome has been previously proved for indicators based on 2-m air temperature only (Pascal et al. 2006), the present one extends it to an environmental setting where humidity, wind and radiation also play a role. The association of PEMs to unusually high minimum and maximum UTCI values - 95th and 99.5th percentilesconfirms that the health of the human body can be severely affected when heat stress rises above adaptation levels throughout the day with lack of respite from diurnal heat stress conditions at night. With regard to the 90th and 98th percentiles also investigated in this study, the 90th percentile never occurs as heathealth threshold in any of the cities; the 98th-percentile threshold appears in all but Limoges. Since at least one threshold has to be identified per city and this corresponds exclusively to 99.5th percentile for Limoges, the 98th-percentile threshold has not been further considered.

The combination of UTCI minimum-maximum thresholds appears frequently for different number of consecutive days. Looking at the corresponding POD, FAR, and FB helps identify which day number provides the best performance, that is, for how many days the threshold has to be exceeded in order to cause observed excess mortality (Fig. 5, right panel). For Paris and Lyon PEMs are best associated 
with a sequence of 3 consecutive days with UTCI minimum and maximum values above the 95th-percentile threshold $(\mathrm{POD}=0.81, \quad 0.19 \leq \mathrm{FAR} \leq 0.45, \quad 1 \leq \mathrm{FB} \leq 1.48$ and $0.69 \leq \mathrm{POD} \leq 0.86, \quad 0.31 \leq \mathrm{FAR} \leq 0.46, \quad 1 \leq \mathrm{FB} \leq 1.41$, respectively). Similarly, for Nantes a heat stress spell is defined when the 95th-percentile threshold is exceeded for 3 days, but a duration of 2 days is also indicative for health impacts $(0.74 \leq \mathrm{POD} \leq 0.87,0.21 \leq \mathrm{FAR} \leq 0.44$, $1.04 \leq \mathrm{FB} \leq 1.43$ and $0.78 \leq \mathrm{POD} \leq 0.83,0.24 \leq \mathrm{FAR} \leq$ $0.39,1.09 \leq \mathrm{FB} \leq 1.35$, respectively). For Strasbourg, the UTCI minimum-maximum threshold is associated with PEM when heat stress conditions persist for 2 (95th and 99.5 th percentile, $0.90 \leq \mathrm{POD} \leq 0.91,0.18 \leq \mathrm{FAR} \leq$ $0.36,1.1 \leq \mathrm{FB} \leq 1.4$ ) or 3 days (95th percentiles, $0.7 \leq$ $\mathrm{POD} \leq 1,0.23 \leq \mathrm{FAR} \leq 0.31,1 \leq \mathrm{FB} \leq 1.3)$. For $\mathrm{Li}-$ moges, the 99.5 th percentile is the only present and considers the 1-, 2-, and 3-day options $(\mathrm{POD}=0.6$, $\mathrm{FAR}=0.5, \mathrm{FB}=1.2$ ). For Strasbourg and Limoges, other options rather than the 3 days appear for the shape of the UTCI daily trend during PEMs. In Strasbourg, for example, a decrease in humidity in the second half of the August 2003 heat wave was responsible for a decrease of the UTCI minimum below the 99.5th percentile. In Limoges, the PEM is identified at the beginning of the heat wave, when UTCI values are still increasing toward high stress levels.

Following these results, the combination of minimum and maximum UTCI values at 95th percentiles $\left(15^{\circ} \pm 2^{\circ} \mathrm{C}\right.$ and $34.5^{\circ} \pm 1.5^{\circ} \mathrm{C}$, respectively) at 3 days represents in general the best indicator of heat-attributable PEMs in considered cities, and can be suitable as impact-based thresholds for triggering precautionary public health action plans. It also reveals that nocturnal UTCI values around $15^{\circ} \mathrm{C}$ or above, despite being associated with "no thermal stress," have detrimental effects to human health when associated with daytime strong heat stress levels for sustained periods. In an UTCI-based HHWWS, heat stress thresholds at 95th percentiles can therefore be employed as one level of heathealth warning. The verification analysis, together with the PEM-associated biometeorological conditions described in section $3 \mathrm{C}$, suggests, however, that heat-attributable mortality is strictly associated with enduring conditions when minimum and maximum UTCI values exceed the 99.5th percentile, that is, when days characterized by strong to very strong heat stress are followed by nights with UTCI values around $17^{\circ}-18^{\circ} \mathrm{C}$ or above. Consequently, thresholds at the 99.5th percentile might also be considered in an HHWWS toward the definition of a higher level of warning for very impactful heat-wave events.

\section{e. Extension of UTCI thresholds to study area}

The geographical distribution over France of UTCI values corresponding to the 95 th and 99.5 th percentiles is shown in Fig. 6 (left panel). Minimum and maximum UTCI values increase as percentiles increase and show a nonhomogeneous distribution over the country.

Maximum UTCI thresholds vary from values in the no thermal stress to the very strong heat stress category. At the 95th percentile, for instance, moderate heat stress is the threshold for northwest and southeast regions of continental France, while strong heat stress characterizes most of the country and Corsica. Very strong heat stress is the threshold for a limited area located southwest, in the Aquitaine basin. At higher percentiles, the thresholds for daytime increase correspondingly, with UTCI values moving toward one heat stress category above, that is, from no thermal stress to moderate heat stress, from moderate heat stress to strong heat stress, and from strong heat stress to very strong heat stress. UTCI thresholds in the very strong heat stress reach the highest values within the same stress category.

Thresholds for minimum UTCI are in the no thermal stress category both at the 95th and at the 99.5th percentiles across most France. Their values, however, greatly differ within the region. They vary between $10^{\circ}$ and $20^{\circ} \mathrm{C}$ at the 95 th percentile and between $12^{\circ}$ and $22^{\circ} \mathrm{C}$ at the 99.5 th percentile. These values are in the no thermal stress category but, as already pointed out in previous sections, their association to thresholds at high percentiles with proved health impacts suggests a potentially harmful thermal stress from nighttime environmental conditions.

Further insights on the consequences of heat stress to national public health are provided by the number of consecutive days in which minimum and maximum UTCI exceeded the 95th- and the 99.5th-percentile thresholds, and their distribution across France during notable heat-wave events (Fig. 6, right panel). In August 2003, for instance, thresholds were beaten for more than 1 week in the cities and in the vast majority of the country, indicating the unusually high, extended heat stress conditions as responsible for the exceptional death burden observed in that period. Also in July 1983 France witnessed a heat wave that was, however, more localized and less intense. Day- and nighttime heat stress levels exceeded the 95th percentile for more than 10 days in the northwest and southeast portions of France. The 99.5th percentiles were also overcome but for shorter periods in the same areas. Excess deaths were recorded in Nantes and Lyon (Table 1). Marseille, the second-largest city in France, was one of the most affected (Delarozière and Sanmarco 2004; Pascal et al. 2013). Figure 6 confirms that Marseille, located on the Mediterranean coast, experienced prolonged heat stress levels above the 95th and the 99.5th percentiles. Large-scale maps of health-meaningful thresholds can 

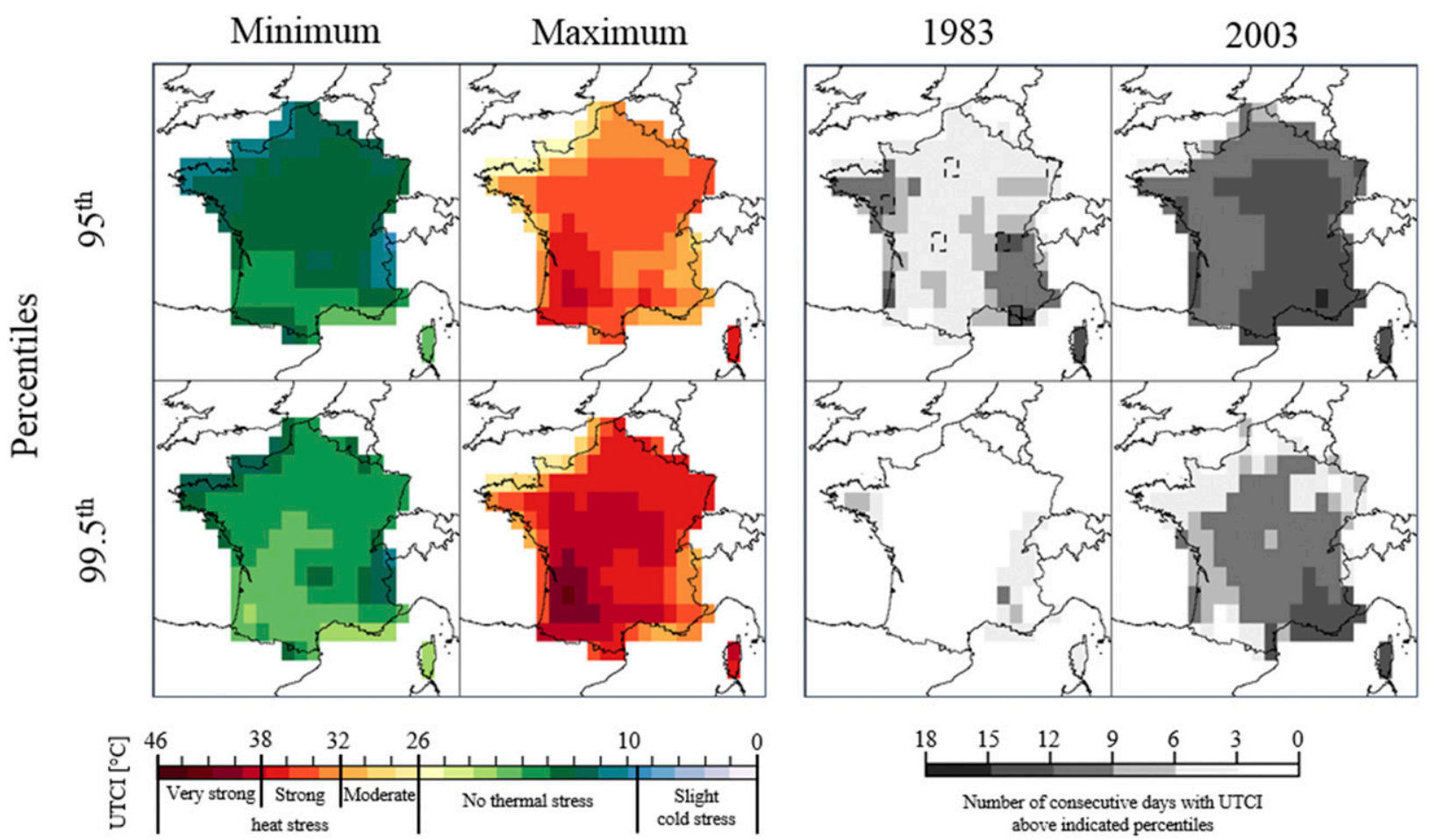

FIG. 6. Geographical distribution over France of UTCI values corresponding to the 95th and 99.5th percentiles of (left) the minimum and maximum UTCI bioclimatology and (right) number of consecutive days when indicated percentiles were exceeded in two major heat-wave events, namely, in July 1983 and August 2003. City locations are as in Fig. 2; the city of Marseille is indicated in the rectangle with continuous-line border.

thus help to provide a background for environmental conditions with severe impacts on mortality also in cities not directly addressed in the current analysis.

\section{f. Comparison of UTCI thresholds and current French HHWWS thresholds}

In Fig. 7 the performance of UTCI city point thresholds with the highest sensitivity and specificity (i.e., minimum and maximum 95th or 99.5th percentiles exceeded for at least 3 consecutive days) is compared with the performance of air temperature thresholds currently employed by the French HHWWS in the regional cities considered in the study (Pascal et al. 2013). For Paris, Lyon, Nantes, and Strasbourg, the percentage of correct alarms, that is, hits, identified by UTCI city point thresholds (on average $68 \%, 64 \%, 69 \%$, and $72 \%$ ) is in general higher than the percentage of correct alarms identified by French HHWWS thresholds $(53 \%, 40 \%$, $57 \%$, and $27 \%$ ). Furthermore, UTCI city point thresholds are associated with lower percentages of false alarms and missed alarms, that is, misses, (on average $13 \%, 36 \%$, $31 \%, 28 \%$ and $19 \%, 23 \%, 20 \%, 13 \%$, respectively) than their temperature-based counterparts $(47 \%, 60 \%, 43 \%$, $73 \%$ and $36 \%, 30 \%, 61 \%, 81 \%$, respectively). This suggests that, for the regional cities considered in the study, an operational HHWWS based on the UTCI could perform better than an operational HHWWS based on air temperature in identifying days with excess mortality. The only exception is represented by Limoges where the skill of the French HHWWS is greater than the skill of UTCI thresholds (percentage of correct, false, and missed alarms equal to $56 \%, 44 \%, 23 \%$ and $50 \%$, $50 \%, 40 \%$, respectively). This might be because the 99.5th percentile is the sole UTCI threshold trigger for that city. Based on one PEM only (occurred in 2003), that percentile might be less robust than a UTCI 95th percentile.

\section{Discussion}

The results presented in this study offer an initial evaluation of the potential usefulness and suitability of the UTCI in the definition of heat-related health hazards. Considering excess mortality as the main impact from heat waves, UTCI thresholds have been identified according to their ability to correctly single out PEMs over a 24-yr period and to do so with high sensitivity and specificity $(0.69 \leq \mathrm{POD} \leq 1,0.19 \leq \mathrm{FAR} \leq 0.46$, $1 \leq \mathrm{FB} \leq 1.48$ ). These results are promising and suggest the potential of a HHWWS where UTCI values are 


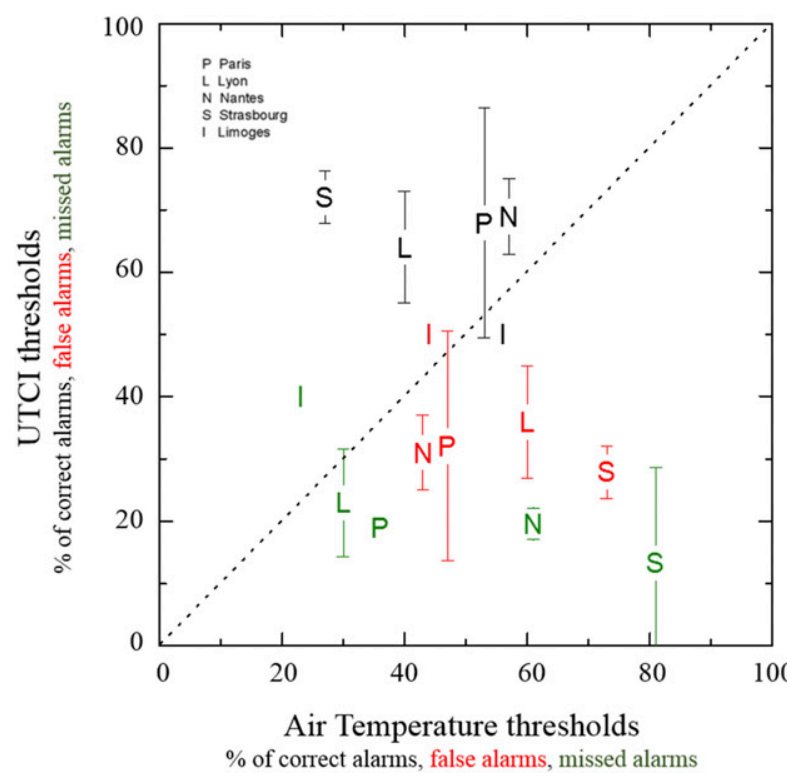

FIG. 7. Performance comparison in terms of percentage of correct, false, and missed alarms between UTCI city point thresholds with the highest sensitivity and specificity (i.e., minimum and maximum 95th- or 99.5th-percentile values exceeded for at least 3 consecutive days) and air temperature thresholds currently employed by the French HHWWS in the regional cities considered in the study. Performances of air temperature thresholds are as in Pascal et al. (2013). Performance percentages have been calculated from corresponding hits, false alarms, and misses (provided in the supplemental material).

forecast with a lead time set by current numerical weather predictions models and trigger warnings when predicted to exceed health-meaningful UTCI thresholds. As the UTCI represents the thermal stress induced by the outdoor environment-air temperature, humidity, wind, radiation-onto the human body, a UTCI-based HHWWS builds upon the capability of individuals to respond to certain environmental conditions, and thus to certain heat stress levels. The association of UTCI thresholds to high percentiles, that is, equal or greater than the 95 th percentile, demonstrates that, when heat stress reaches uncommon intensity (as it happens during a heat wave), individuals get exposed to conditions they are not physiologically acclimatized to and the vulnerable become more at risk of heat-related disorders and potentially death. The importance of considering unusual heat stress conditions both at day and night, and their persistence in time, is also justified in this study and suggests that in a UTCI-based HHWWS warnings should be triggered when minimum and maximum UTCI values simultaneously exceed UTCI thresholds for at least 3 days. These findings represent a step forward in the definition and evaluation of environmental conditions that are potentially detrimental to human health as they relate not to meteorological parameters per se, but to the effects those parameters have on human physiology. They are also in agreement with the outcomes from heat stress health impact studies lead in geographical areas outside France. Błażejczyk et al. (2018), for instance, reported that in Poland a significant increase in mortality is observed in days with strong and very strong heat stress $(12 \%$ and $47 \%$, respectively) with respect to no thermal stress days. They also reported that heat stress is not frequently observed in Poland and its occurrence increases the risk of heatrelated mortality.

It is acknowledged that the relationship between the UTCI, heat stress and PEMs has been investigated for a selected group of regional capitals in France and, as a consequence, results are city specific. The use of highpercentile distributions, however, has already proved a good method to define thresholds in areas where the association between mortality and environmental parameters is unknown (Pascal et al. 2013), and it is therefore applied in this study. Future epidemiological studies on the impact of heat stress at the multicity scale will help to assess this approach. Further research could also investigate the potential of the UTCI as an indicator of heatattributable excess mortality when a new definition is used for PEMs. Possible applications may include the choice of a different reference baseline for mortality, the inclusion of confounding factors such as air pollution that might further exacerbate heat-wave health impacts, and the inclusion of a time lag-usually between 0 and 3 daysbetween heat exposure and the health outcome (i.e., death). Further research could also investigate the relationship between the UTCI and PEMs for specific vulnerable groups, such as the elderly. Age and other physical, socioeconomic, behavioral, and health status factors can affect the population's capacity to respond and adapt to thermal stress and thus increase the risk of heat-related illnesses and deaths (Kovats and Hajat 2008; Margolis 2014; McGregor et al. 2017; Campbell et al. 2018).

It is also worth noting that the verification methodology described in this paper is general and can be applied to assess and compare the utility of other thermal indices and/or weather variables (such as air temperature) in a heat-health watch-warning system context as proposed in other comparative studies (e.g., Hajat et al. 2010; Barnett et al. 2010). It can also be applied to assess the robustness in time (stationarity) of identified UTCIbased thresholds. HHWWSs are by construction based on historical relationships between health impacts and the environment (McGregor et al. 2015). These relationships, however, may vary in time because of a changing bioclimate (an increase in heat stress has been observed in recent decades; Di Napoli et al. 2018) or a 
changing population exposure to socioeconomic and individual risk factors (de'Donato et al. 2015). Future research could address this topic by investigating the effect that selecting different time series length have on the definition of health-impactful heat-wave events. For instance, the air temperature-based thresholds employed in the current French HHWWS and used in the performance comparison against UTCI-based thresholds had been identified using a data period starting from 1973, 6 years before the data period considered in the study (Pascal et al. 2013). A study on stationarity could help to understand whether increasing or decreasing a data period or withholding part of the original dataset could have implications such as changing threshold values, the number of false alarms, or the value of verification metrics.

Another aspect to consider is the characteristics of ERA-Interim data used in input to the computation of the UTCI. The spatial resolution $(\sim 80 \mathrm{~km})$ and land surface scheme (urban tile not included; Balsamo et al. 2009) might not capture features at smaller scale. The presence of systematic biases has also been documented (Decker et al. 2012). More advanced, high-resolution climatological datasets will overcome these issues and provide an optimal platform to calculate UTCI at a scale closer to the city level.

With regard to the feasibility of forecasting the UTCI in an operational setting, tools already exist that can provide such information and have been mentioned in section 1 . Forecast fields of air temperature, humidity, wind, and radiation are usually available as the output products of numerical weather prediction models, such as the ECMWF Integrated Forecast System (IFS) or the National Centers for Environmental Prediction operational Global Forecast System (NCEP GFS). The implementation of real-time UTCI forecasts from above mentioned models would provide insightful feedbacks on the usage of heat stress thresholds in the prediction of heat-wave-induced health hazards, and on the assessment of the skills and uncertainties associated with that prediction. Although performance indicators suggest a potential advantage of using a UTCI-based HHWWS over an air-temperature HHWWS equal to the current French system, forecasts of the UTCI will inherently be subject to the error associated with the forecasts of its input parameters. The predictability skill of wind speed, for instance, is usually lower than the predictability skill of air temperature. This could negatively affect the overall performance of UTCI forecasts (Pappenberger et al. 2015). Since the UTCI is a nonlinear combination of wind with the other input parameters, the final effect of the wind error on the skill of UTCI forecasts cannot be predicted beforehand.
Future work will assess whether the forecast UTCI is superior to simpler parameters, for example, air temperature, for use in an operational heat-health warning system. Furthermore, the current French temperaturebased HHWWS has been running for years and got improved also thanks to feedback of local stakeholders (Pascal et al. 2013). A UTCI system and the thresholds it is based on would equally benefit by being tested in an operational setting.

\section{Conclusions}

In this paper, heat stress thresholds based on the UTCI have been determined from bioclimatological data and characterized on the basis of periods when human mortality increased because of heat waves.

Using France as a test bed, nationwide UTCI maps of heat stress have been computed from 23 years of ERA-Interim meteorological data for the summer season (June-August). Daily minimum, maximum, and mean UTCI maps have been correspondingly extracted and used to calculate UTCI threshold maps at the climatological percentiles usually addressed in the heat-wave research field, namely, the 90th, 95th, 98th, and 99.5th percentiles. For five regional capitals-Paris, Lyon, Nantes, Strasbourg, and Limoges-UTCI city point time series and thresholds have been extracted from respective grid cells of corresponding maps. The selection of those cities is justified by 1) their different geographical location and number of inhabitants, and 2) the definition in the literature of days, called periods of excess mortality (PEMs), when the observed number of deaths exceeds the historical expected value. As proxy for the impact on human health of heat waves, PEMs have been used to identify UTCI city point thresholds by testing the condition that a day with UTCI values above those thresholds corresponds to a day with observed excess mortality.

The present study is the first to demonstrate via verification metrics (probability of detection, false alarm rate, frequency bias) that UTCI city point thresholds at the 95th percentile, exceeded for at least 3 consecutive days both at day- and nighttime $\left(15^{\circ} \pm 2^{\circ} \mathrm{C}\right.$ and $34.5^{\circ} \pm$ $1.5^{\circ} \mathrm{C}$, respectively), have the highest sensitivity and specificity, that is, they identify the maximum number of the days with excess mortality while minimizing misses and false alarms $(0.69 \leq \mathrm{POD} \leq 1,0.19 \leq \mathrm{FAR} \leq 0.46$, $1 \leq \mathrm{FB} \leq 1.48$ ). The UTCI threshold at the 95th percentile provides therefore an impact-based definition for heat waves and can be potentially used in an early warning system to trigger warnings when events with detrimental consequences on human health are predicted. A first comparison with the air temperature-based thresholds currently employed by the French HHWWS supports this 
hypothesis and suggests a possible increased benefit in using the UTCI as a threshold trigger.

As the UTCI is an index with thermo-physiological significance, the association of PEMs to UTCI values equal or above the 95th percentile also proves that excess mortality occurs when individuals are exposed to unusually high (i.e., above adaptation) heat stress levels across the $24 \mathrm{~h}$ and for a sustained period. Moreover, the fact that those UTCI values are close or equal to $32^{\circ}$ and $38^{\circ} \mathrm{C}$, the two limits demarking, respectively, the strong heat stress and very strong heat stress categories, demonstrates that the latter can be applied for a heat-wave definition.

These findings are encouraging and support the UTCI as an indicator able to represent the heat stress conditions responsible for heat waves' mortality burden. Further studies that consider PEMs from other cities in France or in the rest of Europe take population vulnerability into account and employ UTCI data at higher spatial resolution than ERA-Interim could test and potentially extend the presented health-based heat-wave definition to wider geographical areas.

Acknowledgments. This work is supported by the ANYWHERE project (Enhancing Emergency Management and Response to Extreme Weather and Climate Events, Project ID 700099) which is funded by the European Commission's HORIZON2020 Programme. The authors declare they have no conflict of interest.

\section{REFERENCES}

Antics, A., M. Pascal, K. Laaidi, V. Wagner, M. Corso, C. Declercq, and P. Beaudeau, 2013: A simple indicator to rapidly assess the short-term impact of heat waves on mortality within the French heat warning system. Int. J. Biometeor., 57, 75-81, https://doi.org/10.1007/s00484-012-0535-9.

Auffray, A., A. Brisson, A. Tamburini, V. Dziak, V. Maloisel, and S. Martinoni-Lapierre, 2012: Climat de la région RhôneAlpes. Météo-France Tech. Note, 46 pp.

Balsamo, G., A. Beljaars, K. Scipal, P. Viterbo, B. van den Hurk, M. Hirschi, and A. K. Betts, 2009: A revised hydrology for the ECMWF model: Verification from field site to terrestrial water storage and impact in the integrated forecast system. $J$. Hydrometeor., 10, 623-643, https://doi.org/10.1175/2008JHM1068.1.

Barnett, A. G., S. Tong, and A. C. A. Clements, 2010: What measure of temperature is the best predictor of mortality? Environ. Res., 110, 604-611, https://doi.org/10.1016/j.envres.2010.05.006.

Basu, R., and J. M. Samet, 2002: Relation between elevated ambient temperature and mortality: A review of the epidemiological evidence. Epidemiol. Rev., 24, 190-202, https://doi.org/ 10.1093/epirev/mxf007.

Błażejczyk, K., and A. Błażejczyk, 2014: Assessment of bioclimatic variability on regional and local scales in central Europe using UTCI. Scientific Annals of "Alexandru Ioan Cuza", University of IASI, Vol. LX, No. I, S. II C., Geography Series, AL.I.Cuza University Press, 67-82.
— , P. Bröde, D. Fiala, G. Havenith, G. Jendritzky, and B. Kampmann, 2010a: UTCI-New index for assessment of heat stress in man. Przeglad Geogr., 82, 49-72.

,,,,---- I. Holmér, G. Jendritzky, B. Kampmann, and A. Kunert, 2010b: Principles of the new universal thermal climate index (UTCI) and its application to bioclimatic research in European scale. Misc. Geogr., 14, 91-102, https:// doi.org/10.2478/mgrsd-2010-0009.

_ - Y. Epstein, G. Jendritzky, H. Staiger, and B. Tinz, 2012: Comparison of UTCI to selected thermal indices. Int. J. Biometeor., 56, 515-535, https://doi.org/10.1007/s00484-011-0453-2.

— G. Jendritzky, P. Bröde, D. Fiala, G. Havenith, Y. Epstein, A. Psikuta, and B. Kampmann, 2013: An introduction to the universal thermal climate index. Geogr. Pol., 86, 5-10, https:// doi.org/10.7163/GPol.2013.1.

Błażejczyk, A., K. Błażejczyk, J. Baranowski, and M. Kuchcik, 2018: Heat stress mortality and desired adaptation responses of healthcare system in Poland. Int. J. Biometeor., 62, 307-318, https://doi.org/10.1007/s00484-017-1423-0.

Bleta, A., P. Nastos, and A. Matzarakis, 2014: Assessment of bioclimatic conditions on Crete Island, Greece. Reg. Environ. Change, 14, 1967-1981, https://doi.org/10.1007/s10113-0130530-7.

Bröde, P., D. Fiala, K. Błażejczyk, I. Holmér, G. Jendritzky, B. Kampmann, B. Tinz, and G. Havenith, 2012: Deriving the operational procedure for the Universal Thermal Climate Index (UTCI). Int. J. Biometeor., 56, 481-494, https://doi.org/ 10.1007/s00484-011-0454-1.

Burkart, K., F. Meier, A. Schneider, S. Breitner, P. Canário, M. J. Alcoforado, D. Scherer, and W. Endlicher, 2016: Modification of heat-related mortality in an elderly urban population by vegetation (urban green) and proximity to water (urban blue): Evidence from Lisbon, Portugal. Environ. Health Perspect., 124, 927-934, https://doi.org/10.1289/ehp.1409529.

Campbell, S., T. A. Remenyi, C. J. White, and F. H. Johnston, 2018: Heatwave and health impact research: A global review. Health Place, 53, 210-221, https://doi.org/10.1016/j.healthplace.2018.08.017.

Decker, M., M. A. Brunke, Z. Wang, K. Sakaguchi, X. Zeng, and M. G. Bosilovich, 2012: Evaluation of the reanalysis products from GSFC, NCEP, and ECMWF using flux tower observations. J. Climate, 25, 1916-1944, https://doi.org/10.1175/JCLID-11-00004.1.

de'Donato, F. K., and Coauthors, 2015: Changes in the effect of heat on mortality in the last 20 years in nine European cities. Results from the PHASE Project. Int. J. Environ. Res. Public Health, 12, 15 567-15 583, https://doi.org/10.3390/ijerph121215006.

Dee, D., and Coauthors, 2011: The ERA-Interim reanalysis: Configuration and performance of the data assimilation system. Quart. J. Roy. Meteor. Soc., 137, 553-597, https://doi.org/10.1002/qj.828.

Delarozière, J.-C., and J.-L. Sanmarco, 2004: Excess mortality in people over 65 years old during summer heat waves in Marseille. Presse Med., 33, 13-16, https://doi.org/10.1016/S0755-4982(04)98465-5.

Di Napoli, C., F. Pappenberger, and H. L. Cloke, 2018: Assessing heat-related health risk in Europe via the universal thermal climate index (UTCI). Int. J. Biometeor., 62, 1155-1165, https://doi.org/10.1007/s00484-018-1518-2.

D'Ippoliti, D., and Coauthors, 2010: The impact of heat waves on mortality in 9 European cities: Results from the EuroHEAT project. Environ. Health, 9, 37, https://doi.org/10.1186/1476069X-9-37.

Donoghue, E. R., M. A. Graham, J. M. Jentzen, B. D. Lifschultz, J. L. Luke, and H. G. Mirchandani, 1997: Criteria for the diagnosis of heat-related deaths: National Association of 
Medical Examiners. Position paper. National Association of Medical Examiners Ad Hoc Committee on the Definition of Heat-Related Fatalities. Amer. J. Forensic Med. Pathol., 18 , 11-14, https://doi.org/10.1097/00000433-199703000-00002.

Ferro, C., and D. Stephenson, 2012: Deterministic forecasts of extreme events and warnings. Forecast Verification: A Practitioner's Guide in Atmospheric Science, I.T. Jolliffe and D. Stephenson, Eds., John Wiley \& Sons, 185-200.

Fiala, D., G. Havenith, B. Bröde, B. Kampmann, and G. Jendritzky, 2012: UTCI-Fiala multi-node model of human heat transfer and temperature regulation. Int. J. Biometeor., 56, 429-441, https:// doi.org/10.1007/s00484-011-0424-7.

Fischer, E., and C. Schär, 2010: Consistent geographical patterns of changes in high-impact European heatwaves. Nat. Geosci., 3 , 398-403, https://doi.org/10.1038/ngeo866.

Fouillet, A., and Coauthors, 2006: Excess mortality related to the August 2003 heat wave in France. Int. Arch. Occup. Environ. Health, 80, 16-24, https://doi.org/10.1007/s00420-006-0089-4.

García-Herrera, R., J. Díaz, R. M. Trigo, J. Luterbacher, and E. M. Fischer, 2010: A review of the European summer heat wave of 2003. Crit. Rev. Environ. Sci. Technol., 40, 267-306, https:// doi.org/10.1080/10643380802238137.

Gasparrini, A., and Coauthors, 2015: Mortality risk attributable to high and low ambient temperature: A multicountry observational study. Lancet, 386, 369-375, https://doi.org/10.1016/ S0140-6736(14)62114-0.

Gordon, N., and J. Shaykewich, Eds., 2000: Guidelines on performance assessment of public weather services. WMO/TD 1023, 62 pp., http://www.wmo.int/pages/prog/hwrp/documents/FFI/ expert/Guidelines_on_Performance_Assessment_of_Public_ Weather_Services.pdf.

Gosling, S. N., J. A. Lowe, G. R. McGregor, M. Pelling, and B. Malamud, 2009: Associations between elevated atmospheric temperature and human mortality: A critical review of the literature. Climatic Change, 92, 299-341, https://doi.org/ 10.1007/s10584-008-9441-x.

Haiden, T., M. Janousek, J.-R. Bidlot, R. Buizza, L. Ferranti, F. Prates, and F. Vitart, 2018: Evaluation of ECMWF forecasts, including the 2018 upgrade. ECMWF Tech. Memo. 831, 52 pp., https:// www.ecmwf.int/file/275750/download?token=PJqPOL8i.

Hajat, S., and Coauthors, 2010: Heat-health warning systems: A comparison of the predictive capacity of different approaches to identifying dangerously hot days. Amer. J. Public Health, 100, 1137-1144, https://doi.org/10.2105/AJPH.2009.169748.

Havenith, G., and D. Fiala, 2016: Thermal indices and thermophysiological modeling for heat stress. Compr. Physiol., 6, 255-302, https://doi.org/10.1002/cphy.c140051.

- - , and Coauthors, 2012: The UTCI-clothing model. Int. J. Biometeor., 56, 461-470, https://doi.org/10.1007/s00484-011-0451-4.

Heusinkveld, B., G. Sterenborg, G. J. Steeneveld, J. J. Attema, R. J. Ronda, and A. A. M. Holtslag, 2017: Smartphone app brings human thermal comfort forecast in your hands. Bull. Amer. Meteor. Soc., 98, 2533-2541, https://doi.org/10.1175/ BAMS-D-16-0082.1.

Insee, 2018: RP2010 et RP2015 exploitations principales en géographie au 01/01/2017 in "Comparateur de territoire." Institut national de la statistique et des études économiques, https://www.insee.fr/fr/statistiques/2011101?geo=FRANCE-1.

Jendritzky, G., R. de Dear, and G. Havenith, 2012: UTCI-Why another thermal index? Int. J. Biometeor., 56, 421-428, https:// doi.org/10.1007/s00484-011-0513-7.

Kolendowicz, L., M. Półrolniczak, K. Szyga-Pluta, and E. Bednorz, 2018: Human-biometeorological conditions in the southern
Baltic coast based on the universal thermal climate index (UTCI). Theor. Appl. Climatol., 134, 363-379, https://doi.org/ 10.1007/s00704-017-2279-2.

Koppe, C., R. Kovats, G. Jendritzky, and B. Menne, 2004: HeatWaves: Risks and Responses. Health and Global Environmental Change Series, Vol. 2, WHO Regional Office for Europe, 123 pp.

Kovats, R. S., and K. Ebi, 2006: Heatwaves and public health in Europe. Eur. J. Public Health, 16, 592-599, https://doi.org/ 10.1093/eurpub/ck1049.

- and S. Hajat, 2008: Heat stress and public health: A critical review. Annu. Rev. Public Health, 29, 41-55, https://doi.org/ 10.1146/annurev.publhealth.29.020907.090843.

Laaidi, K., M. Pascal, B. Bérat, B. Strauss, M. Ledrans, and P. Empereur-Bissonnet, 2006: Système d'alerte canicule et santé 2006 (Sacs 2006). Institut de Veille Sanitaire Rapport opérationnel, $46 \mathrm{pp}$.

Lemonsu, A., A. Beaulant, S. Somot, and V. Masson, 2014: Evolution of heat wave occurrence over the Paris basin (France) in the 21st century. Climate Res., 61, 75-91, https://doi.org/ $10.3354 / \mathrm{cr} 01235$.

Le Roy Ladurie, E., and D. Rousseau, 2009: Impact du climat sur la mortalité en France, de 1680 à l'époque actuelle. Meteorologie, 64, 43-52.

Lowe, D., K. Ebi, and B. Forsberg, 2011: Heatwave early warning systems and adaptation advice to reduce human health consequences of heatwaves. Int. J. Environ. Res. Public Health, 8, 4623-4648, https://doi.org/10.3390/ijerph8124623.

Lowe, R., J. Ballester, J. Creswick, J.-M. Robine, F. R. Herrmann, and X. Rodó, 2015: Evaluating the performance of a climatedriven mortality model during heat waves and cold spells in Europe. Int. J. Environ. Res. Public Health, 12, 1279-1294, https://doi.org/10.3390/ijerph120201279.

Magnusson, L., D. Richardson, and T. Haiden, 2014: Verification of extreme weather events: Discrete predictands. ECMWF Tech. Memo. 731, 27 pp., https://doi.org/10.21957/1iq131n2c.

Mạkosza, A., and J. Nidzgorska-Lencewicz, 2017: Selected thermal and biothermal aspects of cities in Poland. Pol. J. Nat. Sci., 32, 771-782.

Margolis, H. G., 2014: Heat waves and rising temperatures: human health impacts and the determinants of vulnerability. Global Climate Change and Public Health, K. Pinkerton and W. Rom, Eds., Respiratory Medicine, Vol 7, Humana Press, 85-120.

Matzarakis, A., S. Muthers, and F. Rutz, 2014: Application and comparison of UTCI and PET in temperate climate conditions. Finisterra, 49, 21-31.

McGregor, G., and J. Vanos, 2018: Heat: A primer for public health researchers. Public Health, 161, 138-146, https://doi.org/10.1016/ j.puhe.2017.11.005.

_- P. Bessemoulin, K. Ebi, and B. Menne, 2015: Heatwaves and Health: Guidance on Warning-System Development. World Meteorological Organization, $96 \mathrm{pp}$.

_- A. Bone, and F. Pappenberger, 2017: Meteorological risk: extreme temperatures. Science for Disaster Risk Management 2017: Knowing Better and Losing Less, K. Poljanšek et al., Eds., Publications Office of the European Union, 257-270.

Mooney, P. A., F. J. Mulligan, and R. Fealy, 2011: Comparison of ERA-40, ERA-Interim and NCEP/NCAR reanalysis data with observed surface air temperatures over Ireland. Int. J. Climatol., 31, 545-557, https://doi.org/10.1002/joc.2098.

Murage, P., S. Hajat, and R. S. Kovats, 2017: Effect of nighttime temperatures on cause and age-specific mortality in 
London. Environ. Epidemiol., 1, e005, https://doi.org/10.1097/ EE9.0000000000000005.

Nastos, P., and A. Matzarakis, 2012: The effect of air temperature and human thermal indices on mortality in Athens, Greece. Theor. Appl. Climatol., 108, 591-599, https://doi.org/10.1007/ s00704-011-0555-0.

Nemeth, A., 2011: Changing thermal bioclimate in some Hungarian cities. Acta Climatol. Chorol., 44-45, 93-101.

Pappenberger, F., G. Jendritzky, H. Staiger, E. Dutra, F. Di Giuseppe, D. S. Richardson, and H. L. Cloke, 2015: Global forecasting of thermal health hazards: The skill of probabilistic predictions of the universal thermal climate index (UTCI). Int. J. Biometeor., 59, 311-323, https://doi.org/10.1007/s00484-014-0843-3.

Pascal, M., and Coauthors, 2006: France's heat health watch warning system. Int. J. Biometeor., 50, 144-153, https://doi.org/ 10.1007/s00484-005-0003-x.

_ - V. Wagner, A. Le Tertre, K. Laaidi, C. Honoré, F. Bénichou, and P. Beaudeau, 2013: Definition of temperature thresholds: The example of the French heat wave warning system. Int. J. Biometeor., 57, 21-29, https://doi.org/10.1007/s00484-0120530-1.

Peel, M. C., B. L. Finlayson, and T. A. McMahon, 2007: Updated world map of the Köppen-Geiger climate classification. Hydrol. Earth Syst. Sci., 11, 1633-1644, https://doi.org/10.5194/ hess-11-1633-2007.

Perkins, S., and L. Alexander, 2013: On the measurement of heat waves. J. Climate, 26, 4500-4517, https://doi.org/10.1175/JCLID-12-00383.1.

Rey, G., E. Jougla, A. Fouillet, G. Pavillon, P. Bessemoulin, P. Frayssinet, J. Clavel, and D. Hémon, 2007: The impact of major heat waves on all-cause and cause-specific mortality in France from 1971 to 2003. Int. Arch. Occup. Environ. Health, 80, 615-626, https://doi.org/10.1007/s00420-007-0173-4.

Richman, M. B., and L. M. Leslie, 2014: Attribution and prediction of maximum temperature extremes in SE Australia. Procedia Comput. Sci., 36, 612-617, https://doi.org/10.1016/ j.procs.2014.09.063.

Robine, J. M., S. L. Cheung, S. Le Roy, H. Van Oyen, C. Griffiths, J. P. Michel, and F. R. Herrmann, 2008: Death toll exceeded 70,000 in Europe during the summer of 2003. C. R. Biol., 331, 171-178, https://doi.org/10.1016/j.crvi.2007.12.001.

Russo, S., J. Sillmann, and E. Fischer, 2015: Top ten European heatwaves since 1950 and their occurrence in the coming decades. Environ. Res. Lett., 10, 124003, https://doi.org/10.1088/ 1748-9326/10/12/124003.
Semenza, J. C., J. E. McCullough, W. D. Flanders, M. A. McGeehin, and J. R. Lumpkin, 1999: Excess hospital admissions during the July 1995 heat wave in Chicago. Amer. J. Prev. Med., 16, 269277, https://doi.org/10.1016/S0749-3797(99)00025-2.

Sharpe, M. A., C. E. Bysouth, and R. L. Stretton, 2018: How well do Met Office post-processed site-specific probabilistic forecasts predict relative-extreme events? Meteor. Appl., 25, 2332, https://doi.org/10.1002/met.1665.

Sheridan, S., and L. Kalkstein, 2004: Progress in heat health warning system technology. Bull. Amer. Meteor. Soc., 85, 1931-1941, https://doi.org/10.1175/BAMS-85-12-1931.

Simmons, A. J., K. M. Willett, P. D. Jones, P. W. Thorne, and D. P. Dee, 2010: Low-frequency variations in surface atmospheric humidity, temperature, and precipitation: Inferences from reanalyses and monthly gridded observational data sets. J. Geophys. Res., 115, D01110, https://doi.org/10.1029/ 2009JD012442.

Simonet, J., 1985: Vague de chaleur de juillet 1983: Étude épidémiologique et physiopathologique. Faculté de Médecine, Université Marseille, $161 \mathrm{pp}$.

Szczypta, C., J.-C. Calvet, C. Albergel, G. Balsamo, S. Boussetta, D. Carrer, S. Lafont, and C. Meurey, 2011: Verification of the new ECMWF ERA-Interim reanalysis over France. Hydrol. Earth Syst. Sci., 15, 647-666, https://doi.org/10.5194/hess-15647-2011.

Urban, A., and J. Kyselý, 2014: Comparison of UTCI with other thermal indices in the assessment of heat and cold effects on cardiovascular mortality in the Czech Republic. Int. J. Environ. Res. Public Health, 11, 952-967, https://doi.org/10.3390/ ijerph110100952.

Wagner, V. U. A., C. Calmet, and M. Pascal, 2018: Evolution of heat waves and associated mortality in France, 2004-2014. Bull. Epidemiol. Hebd., 16-17, 320-325.

Watkins, L. E., 2014: Detecting heat waves: Comparison of various heat wave definitions with excess mortality. Masters dissertation, Dept. of Geosciences, Mississippi State University, UMI 1562986, $97 \mathrm{pp}$.

Wolf, T., G. McGregor, and A. Analitis, 2014: Performance assessment of a heat wave vulnerability index for Greater London, United Kingdom. Wea. Climate Soc., 6, 32-46, https:// doi.org/10.1175/WCAS-D-13-00014.1.

Xu, Z., G. FitzGerald, Y. Guo, B. Jalaludin, and S. Tong, 2016: Impact of heatwave on mortality under different heatwave definitions: A systematic review and meta-analysis. Environ. Int., 89-90, 193 203, https://doi.org/10.1016/j.envint.2016.02.007. 